\title{
Bioethical Cases within Clinical Trials During COVID-19; Vision towards a New Design Focused on the Patient's Safety and Needs
}

\author{
María Fernanda Alpizar, Jesus Manuel De Aldecoa and Melchor Alpizar-Salazar* \\ Specialized Centre for Diabetes, Obesity and Prevention of Cardiovascular Diseases, CEDOPEC, S.C. Mexico \\ *Corresponding author: Melchor Alpizar-Salazar, MD, PhD, FACE Specialized Centre for Diabetes, Obesity and Prevention \\ of Cardiovascular Diseases, CEDOPEC, S.C. Mexico
}

\section{ARTICLE INFO}

Received: 幽 February 26, 2021

Published: 幽 March 09, 2021

Citation: María Fernanda A, Jesus Manuel De A, M Alpizar-Salazar. Bioethical Cases within Clinical Trials During COVID-19; Vision towards a New Design Focused on the Patient'S Safety and Needs. Biomed J Sci \& Tech Res 34(3)-2021. BJSTR. MS.ID.005556.

\begin{abstract}
Current global pandemic implications on health emerge as elements to transform the medical view of other pathologies and medical phenomena. This view must be consolidated through, innovative view, resilience, experience and a profound empathy and clinical approach with the patients. In countries like Mexico, with high chronic and metabolic population indexes, this new view must engage in order to comprehend that the medical global status changed as COVID-19 modified behavioral patterns on other pathologies. Approaching patients in the actual world scenario means a personalized focus in the design of Clinical Trials. This focus gives life to an upgraded statistical panorama and an overall satisfaction of patients' needs.
\end{abstract}

\section{Introduction}

The world is currently undergoing a pandemic that has forced everyone to familiarize themselves with the term COVID-19, an infectious disease caused by the severe acute respiratory syndrome coronavirus 2 (SARS-CoV-2) [1,2]. This pandemic has led to significant loss worldwide starting December 2019, reaching Mexico on February 2020 and still going strong [3] is a vulnerable country in this regard, considering its population has a very high prevalence of cardiometabolic illness, a mayor risk factor for a bad prognosis regarding COVID-19. This has to do with the effect that these illnesses have on the immune system and the chronic inflammatory state they sponsor [4,5]. The pandemic caused by COVID-19 has brought out hard questions regarding ethics that warrant careful consideration for solid decision making that protects the rights and health of our patients $[6,7]$.

Research centers in Mexico as in general are responsible for the health of their subjects and patients which is why it is so crucial that they uphold sanitary and institutional directives and guidelines to minimize risk during studies and treatments. New ways to carry on with these experimental studies have had to be developed. Some have implemented home delivery systems for medicines and equipment to prevent unnecessary exposure by going to a center or clinic. However, research product storage and handling is delicate and must follow adequate procedure and documentation. Through it all, patient/subject health must remain the priority of all health personnel. Preventive medicine is another subject that has gained importance throughout these hard times, recognizing that healthy habits on a daily basis decrease the chances of a poor prognosis after contracting SARS-CoV-2.

Preventive medicine also entails doing all that we can to avoid spreading this very infectious disease through protection gear and precise screening for all health-related personnel. This profession has been tested specially during these times of uncertainty and urgency combined, knowing that there are no definitive answers regarding treatments or cures, still doctors are expected to know how to proceed and must make decisions that will impact lives while protecting patient rights, legal and bioethical aspects [8]. 
Perhaps the most dangerous characteristic of SARS-CoV-2 is its novelty and the lack of knowledge it comes with. Research centers across the globe are speeding towards finding treatment options as well as vaccines, but there are no real shortcuts for this, and good clinical practices must be observed throughout [6].

\section{Case Report}

Male patient that enters a phase 3 pharmacological study with moderate rheumatoid arthritis. At baseline presenting oral temperature of $36.2 \mathrm{oC}$, respiratory rate of $18 \mathrm{rpm}$, and body weight of $70.4 \mathrm{~kg}$. Across the study, a $20 \%$ improvement in joint counts was documented (compared to a first visit baseline) with a suitable CDAI (Clinical Disease Activity Index). The subject was diagnosed with COVID-19 at approximately week 84 of the study, causing a halt on his participation in the study since the drug involved had immunosuppressant activity. This has been the case for countless studies probably throughout the world, scientists still don't fully comprehend all aspects of COVID-19 and this means more preventive measures need to take place to avoid furthering risks. Questions such regarding whether these subjects may re-enter the study after the infection has resolved itself and if so, when are still to be answered. This should be thought out in terms of analyzing possible repercussions of the disease and their length.

\section{Bioethics Related Questions in the Current Pandemic}

a) Regarding health centers that also conduct clinical research, should the priority be on the general consults with patients or on affected research studies?

According with the Good Clinical Practice principles and COVID-19 support guidelines, the priority should always be on patient health, however, research is crucial as well for many cases that depend on novel treatment opportunities.

b) In what way is patient opinion valued with respect to patients positive for COVID-19 that enter studies that seek new treatment options?

Informed consent must be obtained in every single case to submit any subject to a given study, given the nature of the pandemic though, certain aspects can be compromised and should be looked at carefully to avoid furthering the risks with the urgency and unknown variables of the situation.

\section{Case Report}

Sixty-seven-year-old male patient diagnosed with obesity, hypertension, heart failure, and hyperuricemia. Being treated with dietary and lifestyle measures, metoprolol, furosemide, spironolactone, and acetylsalicylic acid. Attended his last medical consultation on November $17^{\text {th }}, 2020$ under COVID-19 safety measures. A family member notified the center of his passing, referring that it was sudden and without hospitalization. This was the case of a patient with several risk factors. His previous health state left him vulnerable, with immunodeficiency and chronic systemic inflammation. Unfortunately, the pandemic caused him to skip routine medical visits and therefore his previous conditions might have not been under control. This is one of the silent and most dangerous consequences of this situation. Many patients are rightly scared to visit their physicians for routine check-ups because they might contract COVID-19, however, this also leads to them being left more susceptible to a worse prognosis might them get sick. Propper control of any underlying illness is crucial for anybody to be able to fight off any infection. Although not ideal, telemedicine might be a possible answer to this problem during these times, this may be a way for doctors to keep tabs on their patients without unnecessarily exposing them to the virus.

\section{Bioethics Related Questions in the Current Pandemic}

a) Is the safety of non-urgent chronic cases being looked after?

Every clinic must follow general recommendations to some extent, this however, might not be enough to avoid possible contagions.

b) How often and in what way is medical personnel updated on upcoming information on COVID-19 treatments and findings?

Generally, every physician has a different approach on this, since this does not just apply to the current pandemic, medical research is constantly updated and doctors in every specialty must self-educate to stay current and relevant.

\section{Conclusion}

Bioethics enforce necessary regulations that help guarantee patient/subject safety, which makes this a priority issue. We are undergoing an unfamiliar situation worldwide, a devastating pandemic that has gone on for over a year now, however, this situation is not the only current health threat affecting many people. A great deal of other chronic illnesses and infectious diseases are not holding back, which is why research must go on. Preventive measures are of the essence to lower vulnerability in the general population. One of the lessons this pandemic has left us with is the importance of taking care of our patients and making sure they take care of themselves as well because any disease will have a stronger toll on those left vulnerable by previous illness specially if it goes untreated. The important thing to remember is that the ultimate goal is patient well-being. Respect for life and its quality should guide health personnel's decisions to avoid wrongdoing. 


\section{References}

1. Barazzoni R, Bischoff SC, Breda J, Wickramasinghe K, Krznaric Z, et al (2020) ESPEN expert statements and practical guidance for nutritional management of individuals with SARS-CoV-2 infection. Clin Nutr 39: 1631-1638.

2. Budhwar S, Sethi K, Chakraborty M (2020) A Rapid Advice Guideline for the Prevention of Novel Coronavirus Through Nutritional Intervention. Curr Nutr Rep 9(3): 119-128.

3. (2020) Subsecretaría de Prevención y Promoción de la Salud. Comunicado Técnico Diario Nuevo Coronavirus en el Mundo (COVID-19). Secr Salud pp. 1-2.

4. Carter SJ, Baranauskas MN, Fly AD (2020) Considerations for Obesity, Vitamin D, and Physical Activity Amid the COVID-19 Pandemic. Obesity 28(7): 1176-1177.

\section{ISSN: 2574-1241}

DOI: $10.26717 /$ BJSTR.2021.34.005556

Melchor Alpizar-Salazar. Biomed J Sci \& Tech Res

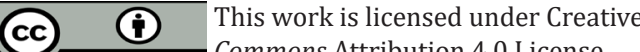

Submission Link: https://biomedres.us/submit-manuscript.php
5. Jayawardena R, Sooriyaarachchi P, Chourdakis M, Jeewandara C, Ranasinghe P (2020) Enhancing immunity in viral infections, with special emphasis on COVID-19: A review. Diabetes Metab Syndr Clin Res Rev 14(4): 367-382.

6. Druml C (2020) COVID-19 and ethical preparedness? Wien Klin Wochenschr 132: 400-402.

7. Kim SYH, Grady C (2020) Ethics in the time of COVID: What remains the same and what is different. Neurology 94(23): 1007-1008.

8. Pastor LM (2020) Nota del Editor: COVID-19 y Bioética. Cuad Bioet 31 131-138.

$\begin{array}{ll}\text { BIOMEDICAL } & \text { Assets of Publishing with us } \\ \text { RESEARCHES } & \text { - Global archiving of articles } \\ \text { - Immediate, unrestricted online access }\end{array}$

